\title{
Samambaias da Estação Ecológica do Panga, Uberlândia, Minas Gerais, Brasil: Anemiaceae, Aspleniaceae, Cyatheaceae e Lygodiaceae
}

\author{
Adriana A. Arantes ${ }^{1,3}$, Jefferson Prado ${ }^{1} \&$ Marli A. Ranal ${ }^{2}$
}

\begin{abstract}
Resumo
(Samambaias da Estação Ecológica do Panga, Uberlândia, Minas Gerais, Brasil: Anemiaceae, Aspleniaceae, Cyatheaceae e Lygodiaceae) O presente trabalho apresenta o levantamento das famílias Anemiaceae, Aspleniaceae, Cyatheaceae e Lygodiaceae da Estação Ecológica do Panga e traz o tratamento taxonômico de suas espécies. A Estação Ecológica do Panga abrange 409,5 ha e está situada a $30 \mathrm{~km}$ ao sul de Uberlândia, MG, entre as coordenadas $19^{\circ} 09^{\prime} 20^{\prime \prime}-19^{\circ} 11^{\prime} 10^{\prime \prime} \mathrm{S}$ e $48^{\circ} 23^{\prime} 20^{\prime \prime}-48^{\circ} 24^{\prime} 35^{\prime \prime} \mathrm{W}$, entre $740-840 \mathrm{~m}$ de altitude. A área apresenta grande importância ecológica por ser uma das poucas formações de vegetação natural da região e por possuir diferentes fisionomias do bioma Cerrado, como campestres, savânicas e florestais. São tratadas neste artigo quatro famílias e oito espécies. São apresentadas chaves para as famílias, bem como ilustrações, distribuição geográfica e comentários dos táxons.
\end{abstract}

Palavras-chave: Aspleniaceae, cerrado, Cyatheaceae, samambaias, Schizaeales.

Abstract

(Ferns of the Ecological Station of Panga, Uberlândia, Minas Gerais State, Brazil: Anemiaceae, Aspleniaceae, Cyatheaceae and Lygodiaceae) This paper is a floristic survey of the families Anemiaceae, Aspleniaceae, Cyatheaceae, and Lygodiaceae of the Ecological Station of Panga, and provides the taxonomic treatment for its species. The Ecological Station of Panga covers an area of $409.5 \mathrm{ha}$, and is located about $30 \mathrm{~km}$ to the

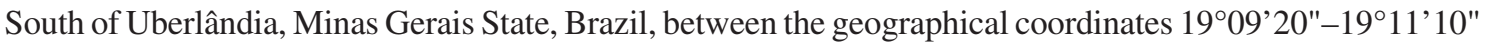
$\mathrm{S}$ and $48^{\circ} 23^{\prime} 20^{\prime \prime}-48^{\circ} 24^{\prime} 35^{\prime \prime} \mathrm{W}$, at $740-840 \mathrm{~m}$ altitude. The area represents a good remnant of the natural vegetation of the region, presenting different savanna and forest physiognomies. We present here the taxonomic treatments for four families and eight species. Identification keys, descriptions, illustrations of diagnostics characters of the families and species, geographical distribution, and comments are presented.

Key words: Aspleniaceae, Cyatheaceae, ferns, savanna, Schizaeales.

\section{INTRODUÇÃo}

OCerradoé considerado um dos 25 hotspots mundiais (Myers et al. 2000; Mittermeier et al. 2005), uma vez que possui um grande número de espécies (Castro et al. 1998; Mendonça et al. 1998) e alta diversidade alfa e beta (Ratter et al. 2003; Bridgewater et al. 2004).

A região do Triângulo Mineiro, onde está situada a área de estudo, é considerada como uma das mais críticas, por restarem poucos remanescentes deste bioma e poucas unidades de proteção integral (Drummond $e t$ al. 2005). Uma dessas unidades é a Estação Ecológica do Panga (EEP), situada no município de Uberlândia, a qual apresenta uma considerável diversidade de fitofisionomias características do bioma Cerrado (Schiavini \& Araújo 1989).

Até o presente, sabe-se que a flora de samambaias e licófitas da área está constituída por 52 espécies, 13 famílias e 22 gêneros. Thelypteridaceae é a mais rica entre as samambaias, com 14 espécies e dois gêneros (Arantes et al. 2007a, b; Arantes et al. 2008), seguida de Pteridaceae e Polypodiaceae, com quatro gêneros e sete espécies cada.

Neste trabalho é apresentado o tratamento taxonômico para Anemiaceae, Aspleniaceae, Cyatheaceae e Lygodiaceae da área, com chaves de identificação, sinonímia, ilustrações, distribuição geográfica e comentários sobre as espécies.

Artigo recebido em 04/2008. Aceito para publicação em 11/2008.

${ }^{1}$ Instituto de Botânica, C.P. 3005, 01061-970, São Paulo, SP, Brasil.

${ }^{2}$ Universidade Federal de Uberlândia, Instituto de Biologia, C.P. 593, 38400-902 Uberlândia, MG, Brasil.

3Autor para correspondência: adrianassisa@ hotmail.com 


\section{Material e Métodos}

A Estação Ecológica do Panga (EEP) abrange 409,5 ha e está situada a $30 \mathrm{~km}$ ao sul do centro da cidade de Uberlândia, MG, entre as coordenadas $19^{\circ} 09^{\prime} 20^{\prime \prime}-19^{\circ} 11^{\prime} 10^{\prime \prime} \mathrm{S}$ e $48^{\circ} 23^{\prime} 20^{\prime \prime}-48^{\circ} 24^{\prime} 35^{\prime \prime} \mathrm{W}$, a $740-840 \mathrm{~m}$ de altitude (Araújo et al. 2002). Aárea apresenta fisionomias comuns do bioma Cerrado como campestres (Campo Sujo, Campo Limpo Úmido), savânicas (Cerrado sentido restrito, Veredas) e florestais (Cerradão, Mata seca e Mata de galeria) (Ribeiro \& Walter 1998).

Os espécimes testemunhos foram coletados, herborizados e depositados nos Herbários HUFU e SP.

Os tratamentos taxonômicos são apresentados em ordem alfabética de famílias, gêneros e espécies, seguindo o sistema de classificação de Smith et al. (2006). As descrições foram elaboradas com base nos caracteres morfológicos dos espécimes coletados na área e, quando necessário, complementadas com materiais de áreas próximas. A terminologia morfológica adotada está de acordo com Lellinger (2002). As descrições das famílias e gêneros foram baseadas nos trabalhos de Mickel (1962; 1981), Moran (1995a,b) e Smith et al. (2006) e as abreviações dos nomes dos autores de táxons seguiram Pichi-Sermolli (1996).

\section{Resultados e Discussão}

$\mathrm{Na}$ área de estudo foram encontradas cinco espécies de Anemiaceae (Anemia ferruginea var. ahenobarba, Anemia hirsuta, Anemia nervosa, Anemia oblongifolia e Anemia phyllitidis); uma espécie de Aspleniaceae (Asplenium formosum); uma de Cyatheaceae (Cyathea delgadii) e uma de Lygodiaceae (Lygodium venustum).

\section{Chaves para as famílias}

1. Plantas arborescentes, pecíolo e raque com espinhos Cyatheaceae

1. Plantas herbáceas ou lianescentes, pecíolo e raque sem espinhos.

2. Frondes escandentes, com crescimento indeterminado Lygodiaceae

2. Frondes não escandentes, com crescimento determinado.

3. Lâmina 1-pinado-pinatífida; soros elípticos, oblongos a lineares Aspleniaceae

3. Lâmina inteira a 1-3 pinada, raro pinatífida; soros reunidos em pinas proximais e estas modificadas em forma de panículas Anemiaceae

As famílias Anemiaceae e Lygodiaceae pertencem à ordem Schizaeales que é monofilética, com registros fósseis do início do Jurássico, e amplamente distribuída nas regiões tropicais e sul temperadas (Moran 1995a; Collinson 1996).

Classicamente esta ordem era formada por apenas uma família, Schizaeaceae, caracterizada como uma família de samambaias leptosporangiadas basais, constituída por cinco gêneros, Anemia, Lygodium, Actinostachys, Mohria e Schizaea, e aproximadamente 170 espécies (Mickel 1962; Moran 1995a; Skog et al. 2002).
Após um histórico de segregações e uniões entre os seus representantes, baseado principalmente em caracteres morfológicos como hábito de crescimento e aspecto geral (Moran 1995a), recentemente Schizaeaceae foi novamente segregada em três famílias distintas, Anemiaceae, Lygodiaceae e Schizaeaceae s.s. (Wikström et al. 2002; Smith et al. 2006). As principais características deste grupo são as lâminas estéreis e férteis diferenciadas, ausência de soros bem definidos e presença de esporângios com ânulos contínuos, transversos e subapicais (Smith $e t$ al. 2006). 
Anemiaceae Link., Fil. Spec.: 23. 1811.

Plantas terrestres ou rupícolas. Rizoma reptante a subereto, coberto por tricomas pluricelulares. Frondes hemidimorfas a dimorfas; lâmina inteira a 1-3-pinada; pinas proximais modificadas em espigas férteis longamente pediceladas, eretas ou raramente horizontais, com tecido laminar ausente ou reduzido; nervuras livres, dicotômicas ou raramente anastomosadas. Esporângios geralmente sobre o par basal de pinas, às vezes, mais de duas pinas ou todas as pinas modificadas em pinas férteis, geralmente eretas; esporos triletes.

Em Anemiaceae estão incluídas plantas terrestres ou rupícolas, sendo caracterizadas principalmente pela presença de esporângios sobre o par basal de pinas proximal (Smith et al. 2006).

Anemia Sw., Syn. Fil. 6: 155. 1806, nom. cons. Tipo: Osmunda phyllitidis L. (= Anemia phyllitidis (L.) Sw.).

Rizoma curto-reptante, horizontal ou subereto, coberto por tricomas castanho- escuros a alaranjados ou ferrugíneos. Frondes eretas, parcial ou totalmente dimorfas; lâmina 1-3-pinada, raro pinatífida ou inteira, papirácea a coriácea, glabra, tomentosa ou hirsuta; pinas proximais modificadas em espigas férteis, longamente pediceladas, eretas ou raramente horizontais, com tecido laminar reduzido ou ausente; nervuras livres ou anastomosadas, sem nervura inclusa nas aréolas. Esporângios em duas fileiras sobre os últimos segmentos das pinas férteis, sésseis, subglobosos a ovais.

Anemia possui cerca de 120 espécies, com distribuição nos trópicos e subtrópicos, sendo a maioria do Novo Mundo e algumas poucas de ocorrência na África, Índia e ilhas do oceano Índico (Mickel 1981; Moran 1995a; Skog et al. 2002; Smith et al. 2006). O Brasil é o centro de diversidade do gênero, com 70 espécies (Moran 1995a; Øllgaard 2001), sendo que a macrorregião Central e Sudeste ocupa lugar de destaque, com cerca de 33 espécies de Anemia, das quais cerca de 25 são endêmicas (Tryon \& Tryon 1982).

\section{Chave para as espécies de Anemia da E. E. do Panga}

1. Lâmina estéril 1-pinado-pinatissecta a 2-pinado-pinatífido ....... A. ferruginea var. ahenobarba

1. Lâmina estéril 1-pinada ou 1-pinado-pinatífida.

2. Pinas pinatífidas A. hirsuta

2. Pinas inteiras.

3. Pinas flabeliformes a obovais, nervuras livres A. oblongifolia

3. Pinas lanceoladas ou oblongas, nervuras anastomosadas.

4. Pinas lanceoladas, esparsamente pilosas a glabras, base arredondada, margens denteadas A. phyllitidis

4. Pinas oblongas a ovais, densamente pilosas, base truncada a oblíqua, margens inteiras

A. nervosa

Anemia ferruginea var. ahenobarba (Christ.) Mickel, Iowa State J. Sci. 36(4): 430. 1962. Anemia ahenobarba Christ., Pl. Nov. Mineir. 2: 37. 1900. Tipo: BRASIL, "Goyaz, montagnes, copiose, Ule 584, 3203" (holótipo P?, n.v.). Fig. 1a-b

Plantas terrestres ou rupícolas. Rizoma 1,5-2 cm diâm., horizontal, curto-reptante, densamente revestido por tricomas pluricelulares, ferrugíneos, 4-7 mm compr. Frondes 22-45 cm compr., hemidimorfas; pecíolo 9-27 ×0,2$0,4 \mathrm{~cm}$, castanho-claro a amarelado, sulcado adaxialmente, com tricomas semelhantes aos do rizoma; lâmina estéril $12-16 \times 7,5-10 \mathrm{~cm}$, oval a lanceolada, 1-pinado-pinatissecta a 2-pinadopinatífida, coberta por tricomas castanhoalaranjados, pluricelulares, 3-6 mm compr., muitas vezes adpressos; pinas estéreis 4,5-7 
$\times 1,5-3 \mathrm{~cm}$, lanceoladas a ovais, opostas a alternas, o primeiro par de pinas proximais 2pinado-pinatífida, as demais pinas estéreis, pinado-pinatissecta, sésseis a curto-pecioluladas, base obtusa, margens inteiras e ápice pinatífido a pinatissecto; pinas proximais modificadas, com tecido laminar reduzido, eretas, maiores que as estéreis; raque e costa cobertas por tricomas semelhantes aos do rizoma, a maioria de 1-3 mm compr.; nervuras livres, 2-6 bifurcadas.

Material examinado: VIII.1986, M.A. Ranal 383 (HUFU); III.1987, M. A. Ranal 420 (HUFU); VII.1987, M. A. Ranal 472 (HUFU); X.1987, M. A. Ranal 488 (HUFU, SP); XI.1987, M.A. Ranal 491 (HUFU, SP); V.1992, M. A. Ranal 580 (HUFU), 588 (HUFU); V.1992, M. A. Ranal 594 (HUFU); VI.1992, M. A. Ranal 599 (HUFU); II.1993, Araújo et al. 440 (HUFU).

Anemia ferruginea é encontrada em Honduras, Colômbia, Venezuela, Guiana, Suriname, Guiana Francesa, Equador, Peru, Bolívia e Brasil, onde se distribui por todo o território. Mickel (1962) separa a variedade ahenobarba por suas lâminas 2-pinado-pinatífidas, com os segmentos agudos a acuminados. No Brasil, esta variedade está restrita ao Nordeste (Bahia), Centro-Oeste (Mato Grosso e Goiás), Sudeste (Minas Gerais) (Prado \& Labiak 2003) e Distrito Federal (Silva $\&$ Barros 2005). Na EEP ela ocorre em ambientes mais abertos, como campos sujos e barrancos de voçorocas.

As características distintivas desta variedade são rizoma horizontal, tomentoso, com tricomas ferrugíneos; o primeiro par de pinas proximais 2-pinado-pinatífida, lobos e ápice das pínulas agudos e presença de tricomas pluricelulares longos, muitas vezes adpressos, com até $6 \mathrm{~mm}$ compr.

Anemia hirsuta (L.) Sw., Syn. Fil.: 155. 1806. Osmunda hirsuta L., Sp. Pl. 1064. 1753. Lectótipo: escolhido por Lellinger, Proc. Biol. Soc. Wash. 98: 387. 1985: Plumier, Traité Foug. Amer. t. 162. 1705.

Fig. 1c-d

Plantas terrestres ou rupícolas. Rizoma 0,5-1,2 cm diâm., curto-reptante, densamente revestido por tricomas pluricelulares, alaranjados, 4-10 mm compr. Frondes $12-25 \mathrm{~cm}$ compr., hemidimorfas; pecíolo 3-13,6 × 0,1-
0,2 cm, castanho-claro a amarelado, sulcado adaxialmente, com tricomas semelhantes aos do rizoma; lâmina estéril 8-11,5×3,5-7,5 cm, oval a oblonga, 1-pinado-pinatífida, hirsuta, adaxialmente coberta por tricomas curtos, castanho-claros, pluricelulares, ca. $1 \mathrm{~mm}$ compr., ápice pinatífido ou semelhante às pinas laterais; pinas estéreis $2-4,2 \times 0,6-2 \mathrm{~cm}$, lanceoladas, opostas a alternas, pinatífidas, sésseis, base oblíqua, margens crenadas; pinas proximais férteis modificadas, com tecido laminar reduzido, eretas, maiores que as estéreis; raque pilosa, com tricomas semelhantes aos do rizoma, a maioria de 1-3 mm compr.; nervuras livres, 2-4 bifurcadas.

Material examinado: X.1987, M. A. Ranal 487 (HUFU, SP); IV.1992, M. A. Ranal 564 (HUFU, SP). Anemia hirsuta está entre as espécies do gênero com maior distribuição no neotrópico, ocorrendo no México, América Central, Antilhas, Colômbia, Venezuela, Equador, Peru, Bolívia e Brasil (Moran 1995a; Mickel \& Smith 2004).

Difere das demais espécies do gênero que ocorrem na EEP pelo menor porte $(12-25 \mathrm{~cm}$ compr.) e pinas pinatífidas, sésseis de base oblíqua e margens crenadas. Ocorre sobre barrancos nas margens dos corpos d'água, sendo também coletada sobre barrancos de voçoroca, em área alterada.

Anemia nervosa Pohl, Fl. bras. 1(2): 193. 1859. Síntipos: BRASIL, "habitat in silvis supra Serra do Mar, prov. Sebastianopolitanae: Pohl s.n. (W?, n.v.); Bahium: Blanchet s.n. (W?, n.v.).

Fig. 1e-f

Plantas terrestres ou rupícolas. Rizoma 1,5-2 cm diâm., curto-reptante, densamente revestido por tricomas pluricelulares, 4-7 mm compr. Frondes 18-40 cm compr., hemidimorfas; pecíolo $6,5-27 \times 0,1-0,4 \mathrm{~cm}$, castanho-claro a amarelado, sulcado adaxialmente, com tricomas semelhantes aos do rizoma; lâmina estéril 13-20 ×6,5-11,5 cm, oval a lanceolada, 1-pinada, coberta por tricomas castanhoalaranjados, pluricelulares, 3-6 mm compr.; pinas estéreis inteiras, 4,5-6 × 1,2-2,7 cm, oblongas a ovais, opostas a alternas, sésseis a curto-pecioluladas, base truncada a oblíqua, margens inteiras, ápice agudo a obtuso; pinas 


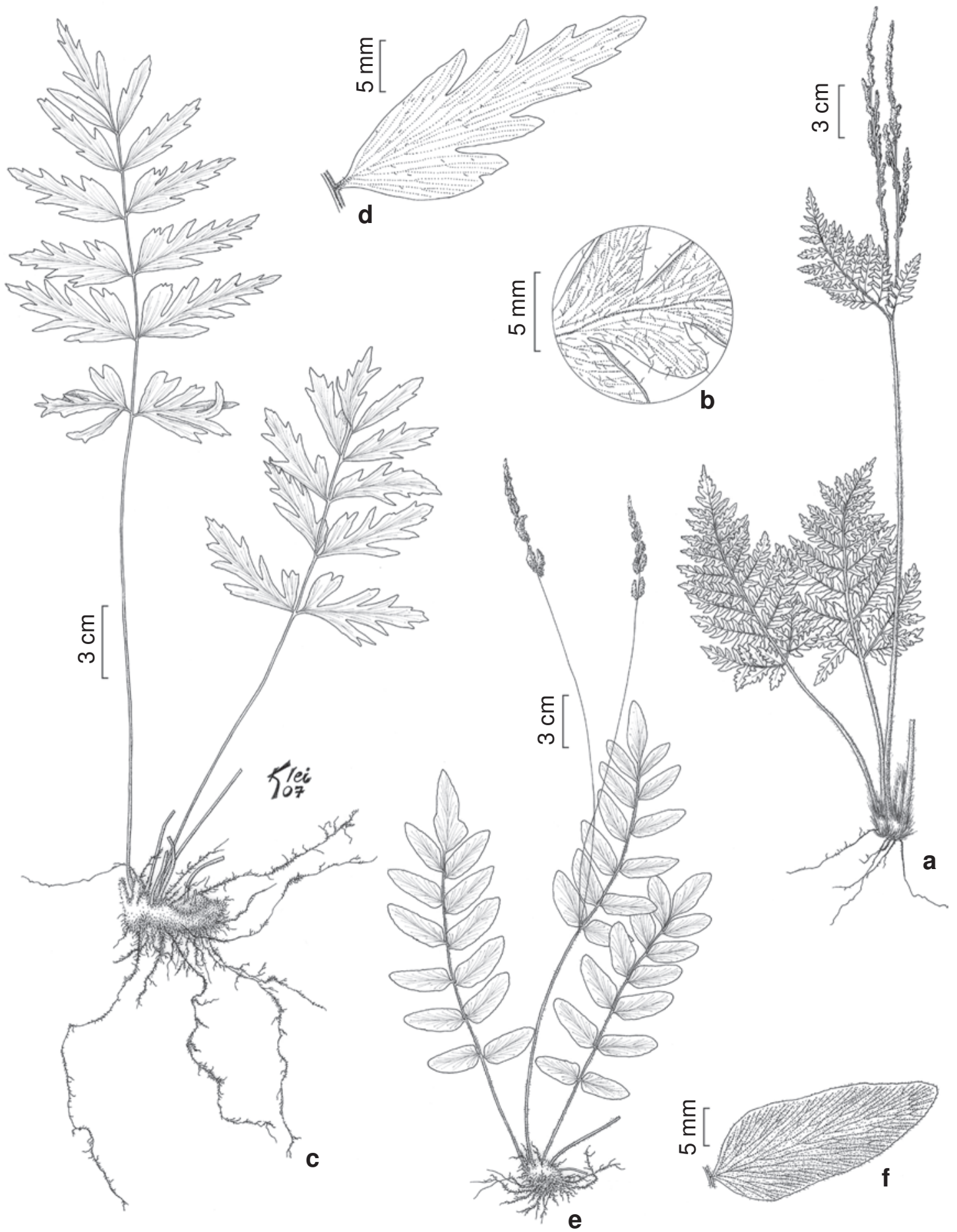

Figura 1 - a-b. Anemia ferruginea var. ahenobarba - a. hábito; b. detalhe da face abaxial da pina mostrando as nervuras e os tricomas. c-d. Anemia hirsuta - c. hábito; d. detalhe da face adaxial da pina pinatífida mostrando as nervuras e os tricomas. e-f. Anemia nervosa - e. hábito; f. detalhe da face adaxial da pina mostrando as nervuras e os tricomas. (a-b Araújo et al. 440; c-d Ranal 564; e-f Ranal 561). 
férteis modificadas, com tecido laminar reduzido, eretas, maiores que as estéreis; raque e costa cobertas por tricomas semelhantes aos do rizoma, a maioria de 1-3 mm compr.; nervuras 2-6 bifurcadas, anastomosadas a partir do terço superior próximo à margem. Material examinado: V.1987, M. A. Ranal 430(HUFU, SP); IV. 1992, M. A. Ranal 561 (HUFU, SP); XI.1994, M. A. Ranal 604 (HUFU); X.1997, A. A. Arantes 770 (HUFU, SP).

Segundo Mickel (comum. pessoal), Anemia ouropretana Christ é sinônimo de $A$. nervosa, embora o nome $A$. ouropretana tenha sido usado recentemente por alguns autores (Figueiredo \& Salino 2005) para designar esta espécie.

Anemia nervosa pode ser confundida com duas outras espécies da área, $A$. oblongifolia e A. phyllitidis, diferenciandose da primeira pelo seu porte maior (18-40 vs. 8-12 cm compr.) e nervuras anastomosadas. Com relação à segunda espécie, as diferenças estão no tipo de tricomas, menores em $A$. phyllitidis (1-2 vs. 3-6 mm compr.) e no formato das pinas, oblongas a ovais em $A$. nervosa e lanceoladas em A. phyllitidis. Esta espécie é pouco coletada na região do Triângulo Mineiro, e apresenta distribuição restrita aos estados do Mato Grosso, Bahia, Rio de Janeiro (Sehnem 1974), Minas Gerais e Goiás.

Anemia oblongifolia (Cav.) Sw., Syn. Fil. 156. 1806. Osmunda oblongifolia Cav., Icon. 6: 69. 1801. Tipo: PANAMÁ, Née s.n. (holótipo MA, n.v.).

Fig. 2a-b

Plantas terrestres ou rupícolas. Rizoma 1,0-1,5 cm diâm., curto-reptante, densamente revestido por tricomas pluricelulares, alaranjados, 3-5 mm compr. Frondes 4,5-13,5 cm compr., hemidimorfas; pecíolo 1,5-5 $\times 0,1-$ $0,2 \mathrm{~cm}$, castanho-claro a amarelado, sulcado adaxialmente, com tricomas semelhantes aos do rizoma; lâmina estéril 3-11 × 2-3,5 cm, oblonga, 1-pinada, coberta por tricomas castanho-alaranjados a esbranquiçados, pluricelulares, de base dilatada, até $1 \mathrm{~mm}$ compr., às vezes arqueados; pinas estéreis inteiras, $0,8-1,7 \times 0,5-1,1 \mathrm{~cm}$, flabeliformes a obovadas, alternas, sésseis a curto-pecioluladas, base oblíqua, margens crenadas, ápice conforme; pinas férteis modificadas, com tecido laminar reduzido, eretas, maiores que as estéreis; raque, costa e pinas cobertas por tricomas semelhantes aos do rizoma, a maioria de até 1 mm compr.; nervuras livres, 2-6 bifurcadas. Material examinado: III.1987, M. A. Ranal 415(HUFU, SP); VII.1987, M. A. Ranal 476(HUFU); X.1987, M. A. Ranal 489 (HUFU); II.1988, M. A. Ranal 505 (HUFU, SP); IV.1992, M.A. Ranal 574 (HUFU); V.1992, M. A. Ranal 579 (HUFU, SP), 595 (HUFU).

Apresenta distribuição ampla no neotrópico, ocorrendo no México, América Central, Colômbia, Venezuela, Guianas, Equador, Peru, Bolívia, Brasil e norte da Argentina (Moran 1995a). Na EEP, ocorre em locais total ou parcialmente sombreados, em barrancos de voçoroca e margens de corpos d'água.

As pinas flabeliformes a obovadas representam o caráter marcante desta espécie. Difere de Anemia nervosa pelo formato das pinas e suas margens crenadas, além das nervuras que são livres em A. oblongifolia e anastomosadas, a partir do terço superior próximo à margem, em $A$. nervosa.

Anemia phyllitidis (L.) Sw., Syn. Fil. 6: 155. 1806. Osmunda phyllitidis L., Sp. Pl.: 1064. 1753. Lectótipo: designado por Proctor, Ferns Jam.: 77. 1985: Plumier, Traité Foug. Amer. t. 156. 1705.

Fig. 2c-d

Plantas terrestres ou rupícolas. Rizoma 1-1,7 cm diâm., ereto, densamente revestido por tricomas pluricelulares, alaranjados, 3-5 mm compr. Frondes 50-83 cm compr., hemidimorfas; pecíolo $11-49 \times 0,2-0,5 \mathrm{~cm}$, castanho-claro a amarelado, sulcado adaxialmente, às vezes anguloso, com tricomas semelhantes aos do rizoma; lâmina estéril 14-17×7,5-14cm, oblonga a lanceolada, 1-pinada, esparsamente pilosa a glabra, tricomas castanho-alaranjados, pluricelulares, 1-2 mm compr.; pinas estéreis 5,5-9,5 × 1,8-2,6 cm, lanceoladas, opostas a alternas, pecioluladas a curto-pecioluladas, peciólulos com até $3 \mathrm{~mm}$ compr., base arredondada, 


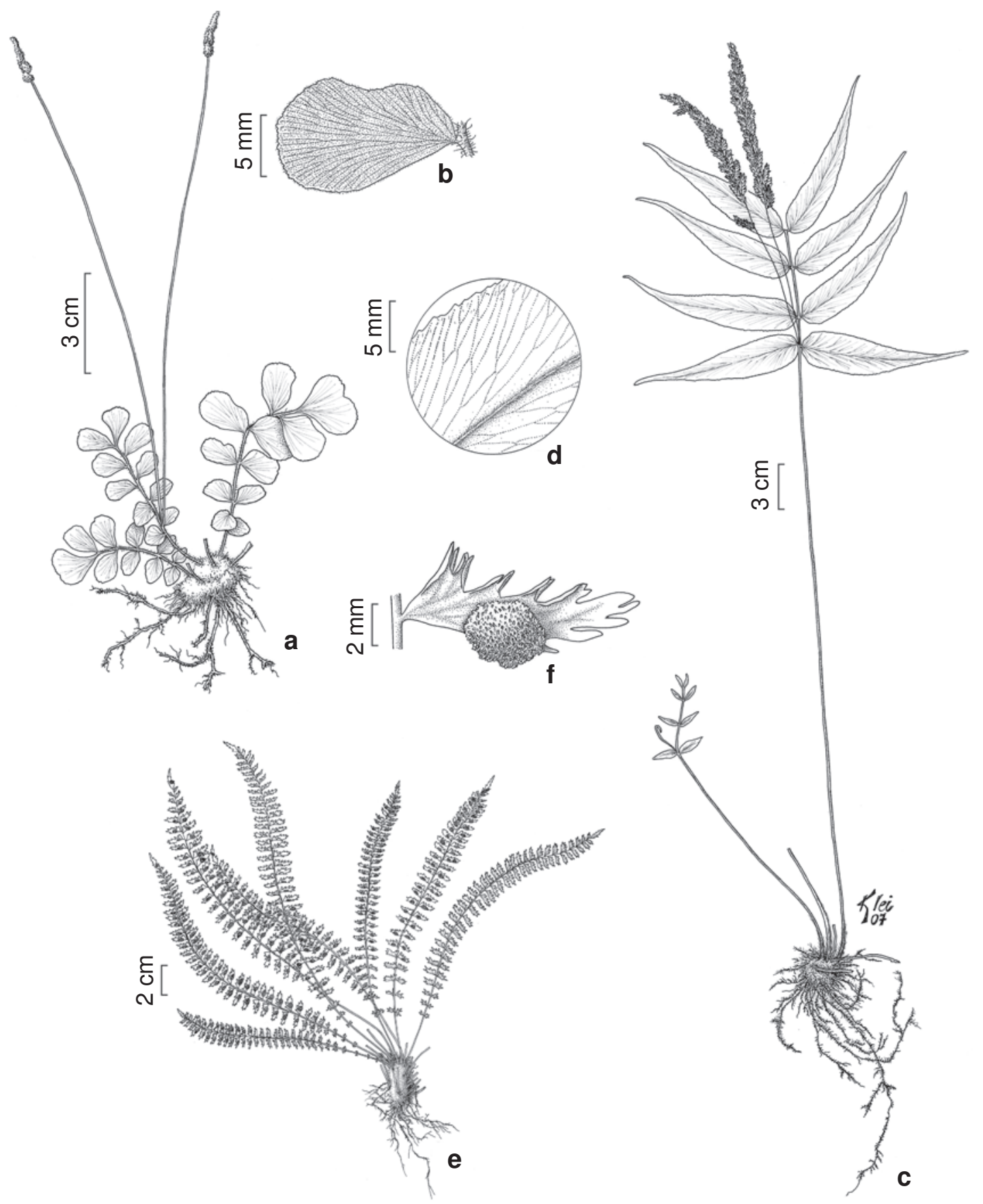

Figura 2 - a-b. Anemia oblongifolia - a. hábito; b. detalhe da face adaxial da pina mostrando as nervuras e os tricomas. c-d. Anemia phyllitidis - c. hábito; d. detalhe da face adaxial da pina mostrando as nervuras anastomosadas. e-f. Asplenium formosum - e. hábito; f. face abaxial da pina, detalhe de um soro (a-b Ranal 505; c-d Ranal 413; e-f Ranal 409). 
margens denteadas, ápice acuminado, pina apical conforme a pinatilobada; pinas férteis modificadas, com tecido laminar reduzido, eretas, maiores que as estéreis; raque e costa adaxialmente cobertas por tricomas semelhantes aos do rizoma, até $3 \mathrm{~mm}$ compr.; nervuras anastomosadas.

Material examinado: VIII.1986, M. A. Ranal 382 (HUFU, SP); III.1987, M. A. Ranal 413 (HUFU, SP), 424 (HUFU, SP), 425 (HUFU); VII.1987, M. A. Ranal 471 (HUFU); IV.1992, M. A. Ranal 569 (HUFU, SP), 572 (HUFU); IX.2004, A. A. Arantes \& M. A. Ranal 1247 (HUFU), 1261 (HUFU); X.2004, A. A. Arantes \& M. A. Ranal 1312 (HUFU), 1313 (HUFU); XI.2004, A. A. Arantes \& M. A. Ranal 1367 (HUFU).

Anemia phyllitidis possui ampla distribuição na América tropical (Mickel \& Smith 2004). Na EEP, A. phyllitidis ocorre em cerradão, cerrado s.s. e em matas seca e de galeria, com preferência por locais sombreados ou próximos a solos úmidos.

Anemia phyllitidis destaca-se, entre as espécies do gênero, pelo porte maior $(50-83 \mathrm{~cm}$ compr.), pinas com margens não recortadas e nervuras nitidamente anastomosadas.

Aspleniaceae Newman, Hist. Brit. Ferns: 6. 1840.

Plantas terrestres, epífitas ou rupícolas. Rizoma ereto, ascendente ou horizontal, com escamas clatradas, castanhas, raro pilosas. Frondes monomorfas, raro dimorfas, pecioladas a ocasionalmente subsésseis; pecíolo com dois feixes vasculares em forma de ' $C$ ' na base, que se fundem em forma de um ' $X$ ' na sua porção distal, não articulado, glabro, com tricomas e/ou escamas clatradas; lâmina inteira a 1-4-pinadopinatífida, glabra, esparso pilosa ou às vezes com diminutas escamas; raque sulcada ou algumas vezes alada adaxialmente, glabra, esparso pilosa ou às vezes com diminutas escamas; nervuras livres, em poucos casos anastomosadas. Soros adjacentes ao lado acroscópico das nervuras, oblongos, elípticos a lineares, com paráfises; indúsio linear a oblongo; esporângios longopedicelados, comânulo interrompido pelo pedicelo, glabros; esporos monoletes, aclorofilados, negros, castanho-claros a amarelados.
Aspleniaceae é monofilética, possui de um a 10 gêneros e cerca de 700 espécies (Smith et al. 2006), com distribuição nas regiões temperadas e tropicais (Sylvestre \& Ramos 2005). A família é considerada bastante homogênea pela quantidade de espécies que abriga (Tryon \& Tryon 1982). No entanto, os recentes estudos moleculares demonstram como incertas a maioria das delimitações genéricas (Smith et al. 2006). A maior parte das espécies pertence ao gênero Asplenium.

De acordo com Moran (1995b), as principais características da família são as escamas clatradas, os soros lineares e os feixes vasculares na base do pecíolo unidos ou não em forma de um ' $\mathrm{X}$ '.

No Brasil, a família está representada por dois gêneros Asplenium, com 69 espécies e quatro variedades, e Antigramma, com três espécies (Sylvestre \& Ramos 2005).

Na EEP, foi encontrada uma espécie, Asplenium formosum.

Asplenium L., Sp. Pl. 2: 1078. 1753. Lectótipo: designado por J. Smith, Hist. Fil.: 316. 1875: Asplenium marinum L.

Plantas terrestres, epífitas ou rupícolas. Rizoma curto-reptante a ereto, ascendente ou horizontal, freqüentemente com escamas clatradas. Frondes monomorfas a raramente dimorfas, pequenas ou médias, raramente grandes, eretas, pendentes ou aderidas ao substrato; pecíolo verde, castanho-escuro ou negro, a maior parte das vezes ligeiramente alado, glabrescente ou com escamas e/ou tricomas principalmente na base; lâmina simples ou 1-3-pinado-pinatífida, deltóide, lanceolada a linear-lanceolada, glabra ou com escamas sobre a raque; nervuras livres, geralmente 1-2-furcadas ou até 5-furcadas no lado acroscópico das pinas proximais das pinas. Soros abaxiais, sobre as nervuras, oblongos a lineares; indúsio persistente, inteiro a erodido; esporângios glabros, pedicelados; esporos bilaterais, negros, com perisporo reticuladocrestado, liso, espinhoso, verrugoso ou papiloso.

Asplenium é cosmopolita, com cerca de 700 espécies (Mickel \& Beitel 1988), ocorrendo 
principalmente nas regiões tropicais e subtropicais. São listadas 83 espécies para a Mesoamérica, sendo 55 dessas ocorrentes em Oaxaca, México (Mickel \& Beitel 1988), 64 espécies ocorrem na Venezuela (Smith 1995) e 69 espécies no Brasil (Sylvestre \& Ramos 2005).

Asplenium formosum Willd., Sp. P1. 5: 329. 1810. Tipo: VENEZUELA, Caracas, Bredemeyer s.n. (holótipo B-Willd. 19908, n.v).

Fig. 2e-f

Plantas rupícolas ou epífitas. Rizoma ereto, 0,5-1 cm diâm., com escamas, 1,5-2 mm compr., lanceoladas, clatradas, brilhantes, bicolores a castanho-escuras, glabras. Frondes 20-27 cm compr., monomorfas; pecíolo 1,5-4 $\times 0,08-0,1 \mathrm{~cm}$, castanho-escuro, brilhante, glabro ou com escamas lineares, alado na face adaxial; lâmina 1-pinado-pinatífida, 15-24,5× 1,8-2 cm, lanceolada, papirácea, 2-6 pares de pinas proximais gradualmente reduzidas, ápice gradualmente reduzido, pinatífido; raque glabra em ambas as faces, brilhante, alada; pinas 0,8 1,1 $\times 0,2-0,4 \mathrm{~cm}, 32-39$ pares, sésseis, oblongas, glabras, ápice agudo ou bifurcado, base oblíqua, margem acroscópica denteada, margem basiscópica inteira; nervuras livres, 6-12 pares por pina, bifurcadas no lado acroscópico proximal. Soros 1 por pina, oblongos a elípticos, submarginais, paralelos à margem basiscópica; indúsio inteiro, glabro.

Material examinado: XI.1986, I. Schiavini s.n. (HUFU 1440); III.1987, M. A. Ranal 409 (HUFU, SP); II.1988, M. A. Ranal503(HUFU); VII.1991, M. A. Ranal 549 (HUFU, SP); IV.1992, M. A. Ranal 560 (HUFU); X.1997, A. A. Arantes 769 (HUFU, HRCB); IV.2000, A. A. Arantes s.n. (HUFU 46849, SP); IX.2004, A. A. Arantes \& R. A. Ranal 1248 (HUFU); X.2004, A. A. Arantes \& R.A. Ranal 1311 (HUFU), 1335 (HUFU), 1336 (HUFU), 1353 (HUFU).

Asplenium formosum é amplamente distribuída no neotrópico, com citações para o México (Mickel \& Beitel 1988), América Central, Antilhas, Colômbia, Guianas, Equador, Peru, Brasil, Bolívia, Paraguai e nordeste da Argentina (Smith 1995). No Brasil, ocorre nos estados do Amazonas, Pará, Goiás, Distrito Federal, Mato Grosso, Mato Grosso do Sul, Ceará,
Pernambuco, Alagoas, Minas Gerais, Rio de Janeiro, São Paulo e Rio Grande do Sul (Sylvestre \& Ramos 2005). Na EEP, está restrita às matas de galeria e mesófila semidecídua de encosta, sempre associada a solos com afloramentos de rocha basáltica.

Esta espécie se distingue das demais que ocorrem na área pelas pinas com margens acroscópicas denteadas e ápice variando de agudo a bifurcado e pelos soros, apenas um por pina, de formato oblongo a elíptico, com disposição submarginal e adjacente à porção basiscópica.

Cyatheaceae Kaulf., Wesen Farrenkr.: 119. 1827.

Plantas terrestres, arborescentes ou subarborescentes. Caule geralmente ereto, raramente delgado e escandente, com escamas e algumas vezes espinhos, comum a presença de cicatrizes foliares, restos de pecíolos, ou envolto por emaranhado de raízes adventícias fibrosas; feixes vasculares policíclicos, dictiostélicos. Frondes geralmente grandes, monomorfas, raro dimorfas; pecíolo espinescente ou não na base, com escamas, intumescido ou não, sulcado adaxialmente, com ou sem aflébias na base; lâmina 1-3-pinadopinatífida, raro simples, glabra a densamente pilosa e com escamas; nervuras livres, raro anastomosadas. Soros circulares, superficiais ou terminais sobre as nervuras ou submarginais; paráfises maiores ou menores que os esporângios; indúsio ausente ou presente, arredondado ou bivalvado, cobrindo completamente ou não os esporângios, umbonados; esporângios curto-pedicelados, com quatro fileiras de células e ânulo oblíquo, não interrompido pelo pedicelo; esporos tetraédricos, triletes, com ornamentação variada, aclorofilados, amarelados.

Cyatheaceae possui distribuição pantropical, com registros fósseis datados do Jurássico e início do Cretáceo (Smith et al. 2006). Esta família, juntamente com Dicksoniaceae, Metaxyaceae e Cibotiaceae, formam um grupo monofilético de samambaias arborescentes (Korall et al. 2006). 
De acordo com o sistema de classificação de Smith et al. (2006), Cyatheaceae inclui cinco gêneros (Alsophila, Cyathea, Gymnosphaera, Hymenophyllopsis e Sphaeropteris) e 600 espécies.

Os caracteres mais usados na distinção da família são a presença de escamas no caule, na base do pecíolo e, muitas vezes, sobre a lâmina e báculo (Tryon \& Stolze 1989; Smith et al. 2006). Na área de estudo foi encontrada somente uma espécie, Cyathea delgadii, abundante no interior das veredas e manchas de matas de galeria junto a estas formações.

Cyathea Sm., Mém. Acad. Roy. Sci. (Turin) 5: 416. 1793. Tipo: Polypodium arboreum L. (= Cyathea arborea (L.) Sm.).

Plantas terrestres, subarbustivas a arborescentes. Caule ereto, com escamas, sem espinhos, geralmente com cicatrizes foliares, restos de pecíolos ou raízes adventícias fibrosas; raro bifurcado. Frondes monomorfas, raro dimorfas; pecíolo liso ou com escamas bicolores ou monocromáticas, setas negras raramente presentes, espinescente principalmente na base; lâmina 1-4-pinada, a maioria é 2-pinadopinatissecta, glabra a densamente pilosa em ambas as faces, tricomas estrigosos, pluricelulares; raque, raquíola e costa espinescentes ou não, tomentosas adaxialmente; pinas inteiras a 2pinado-pinatissecta; nervuras livres. Soros circulares, com receptáculo elevado, com paráfises; indúsio globoso presente ou ausente; esporos tetraédricos, triletes, geralmente 64 por esporângio.

O gênero possui mais de 115 espécies e distribuição tropical (Moran 1995c), do México e sul do Caribe ao norte da Argentina e sul do Brasil (Fernandes 2005). Os caracteres diagnósticos são caule arborescente ou não, escamas do pecíolo com margens inteiras e costa pubescente adaxialmente.

Cyathea delgadii Sternb., Vers. Fl. Vorwelt 1: 47, tab. B. 1820. Tipo: BRASIL, Goiás: Pohl s.n. (holótipo PRC, n.v.).

Fig. 3a-c

Plantas terrestres, arborescentes. Caule ereto, coberto por escamas de 1-2 cm compr., coloridas uniformemente a levemente bicolores, castanhas com as margens mais claras, lanceoladas, ápice acuminado, margens erodidas, basefixas. Frondes 1,25-2,13 m compr., monomorfas; pecíolo 36-62 $\times 0,8-2,3$ $\mathrm{cm}$, piloso, não intumescido, castanho na base e paleáceo distalmente, sulcado adaxialmente, espinescente, escamas na base semelhantes às do caule; lâmina 90-150 × 64-150 cm, lanceolada, 1-2-pinado-pinatissecta; pinas alternas, linear-lanceoladas, acuminadas, sésseis a pecioluladas, peciólulos 3-12 mm compr.; pinas proximais 53-42 × 17-12 cm; pinas medianas $36-23 \times 9-8 \mathrm{~cm}$; pinas distais 8-10×2-2,5 cm; pínulas 3,5-5,5×0,7-1 cm, linear-lanceoladas, ápice acuminado, sésseis a pecioluladas; segmentos crenados e levemente falcados e recurvados no lado acroscópico, levemente alternos, tecido laminar entre as nervuras glabro; raque espinescente, densamente pilosa com tricomas estrigosos, pluricelulares, castanho-claros, principalmente abaxialmente; escamas de 0,5-10 mm compr., oval-lanceoladas, castanho-douradas sobre a costa, raque, raquíola; nervuras bifurcadas, raro simples. Soros circulares, sobre a bifurcação das nervuras; indúsio globoso e inflado, paráfises menores que os esporângios.

Material examinado: III.1987, M. A. Ranal 422 (HUFU); V.1992, M. A. Ranal 583 (HUFU, SP); X.2004, A. A.Arantes \& M. A. Ranal 1305 (HUFU, SP), 1318 (HUFU); XII.2004, A. A.Arantes \& M. A. Ranal 1383 (HUFU), 1388 (HUFU), 1405 (HUFU).

Cyathea delgadii é muito comum no interior de florestas tropicais úmidas e submontanas. Possui distribuição ampla, ocorrendo na Costa Rica, Panamá, Venezuela, Guiana Francesa, Guiana, Trindade, Colômbia, Equador, Peru, Bolívia, Argentina, Paraguai e Brasil (Tryon \& Stoze 1989; Lellinger 1989; Moran 1995c; Smith 1995). Na EEP ela ocorre no interior e bordas de veredas.

Esta espécie destaca-se pelo hábito arborescente, caule aéreo bem desenvolvido e pecíolo espinescente, sulcado e coberto por escamas; lâmina 2-pinado-pinatissecta, chegando a medir 90-150 cm compr.; soros globosos, com indúsio inflado. 

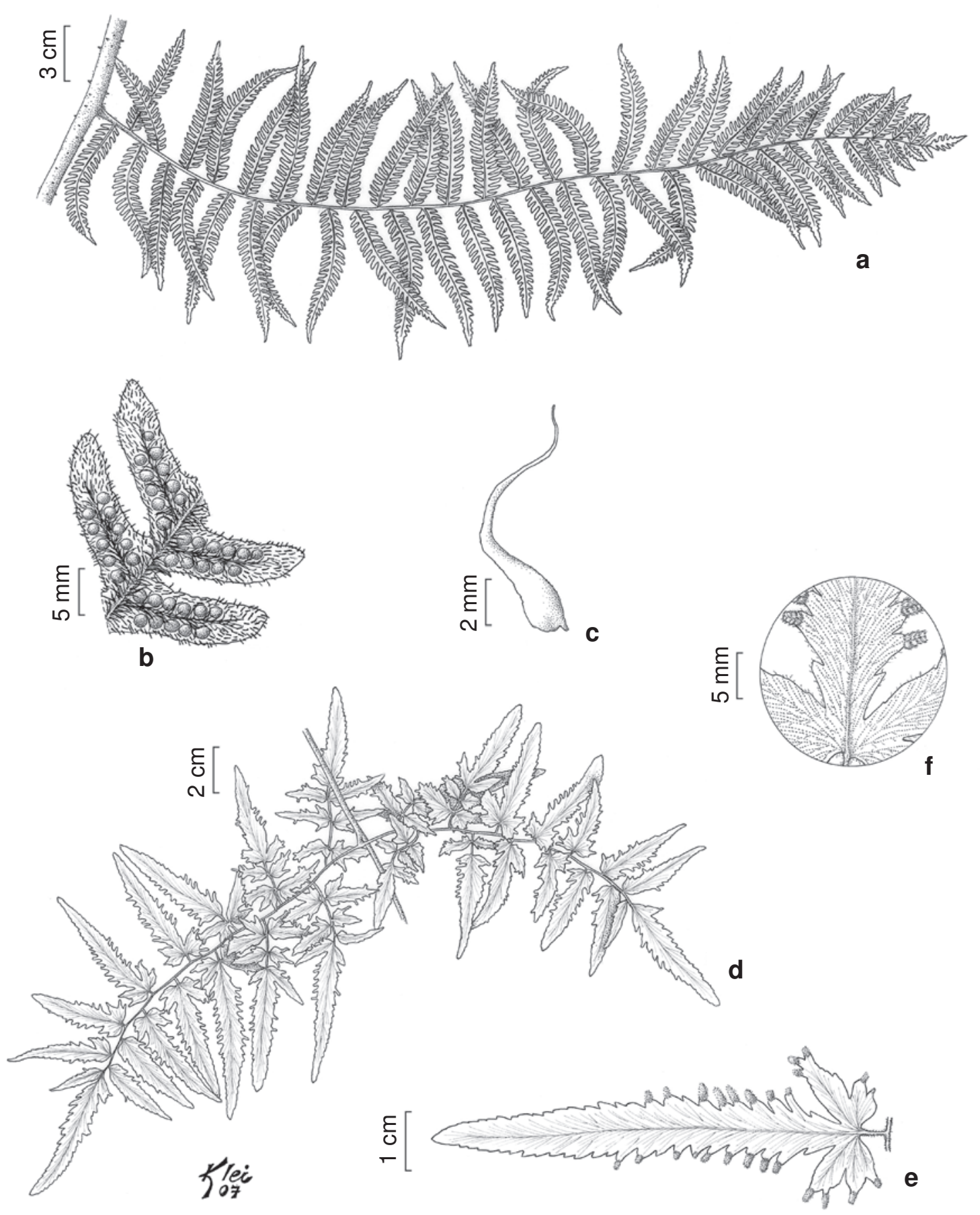

Figura 3-a-c. Cyathea delgadii - a. face adaxial de uma pina proximal; b. face abaxial de parte da pínula, detalhe dos soros e indumento; c. detalhe de uma escama da face abaxial das pinas. d-f. Lygodium venustum - d. parte de uma lâmina em vista adaxial. e. detalhe da pínula na face abaxial; f. detalhe da pínula na face abaxial mostrando as nervuras e soros no ápice dos segmentos. (a-c Arantes \& Ranal 1383; d-f Ranal 412). 
Lygodiaceae M. Roem., Handb. Allg. Bot. 3: 520. 1840.

Plantas terrestres, rizoma reptante, delgado, protostélico. Frondes com crescimento indeterminado, volúveis; lâmina alternadamente pinada; pinas pseudodicotomicamente bifurcadas com uma gema dormente na axila; nervuras livres ou anastomosadas. Soros no ápice dos segmentos; esporângios abaxiais, solitários, 1 por soro, coberto por um falso-indúsio; esporos triletes.

Em Lygodiaceae são incluídas as espécies lianescentes da ordem Schizaeales, representadas por um único gênero, Lygodium, e cerca de 25 espécies (Skog et al. 2002).

Lygodium Sw., Bot. Schrader 1800(2): 106. 1802.

Plantas lianescentes. Rizoma terrestre, com tricomas aciculares, pluricelulares, alaranjados. Frondes com crescimento indeterminado, volúveis, enrolando-se a partir da gema apical da raque, monomorfas; lâmina 1-3-pinado-pinatífida, papirácea, glabra ou com tricomas pluricelulares alaranjados; pinas alternas, pecioluladas; pínulas divididas, palmado-lobadas a pinadas; nervuras livres ou anastomosadas. Soros no ápice dos segmentos; esporângios abaxiais, solitários, 1 por soro, cobertos pelo tecido laminar marginal, falsoindúsio; esporos triletes.

Lygodium apresenta distribuição pantropical, estendendo-se até as zonas temperadas no oeste dos Estados Unidos, Sul da África, Japão e Nova Zelândia, com cerca de 35 espécies, nove delas ocorrendo no Novo Mundo (Moran 1995a). Suas características são incomuns, como as frondes volúveis e de crescimento indeterminado, o que o torna distinto entre os demais gêneros da área.

Na EEP ocorre somente uma espécie, Lygodium venustum.

Lygodium venustum Sw., J. Bot. (Schrader) 1801(2): 303. 1803. Lectótipo: escolhido por Proctor, Fl. Lesser Antill. 2: 51. 1977: BRASIL, Breynius s.n. (S?, n.v.).

Fig. 3d-f

Plantas terrestres. Rizoma não visto; pecíolo 1-1,2 mm diâm., castanho-claro, mais escuro na base, piloso na base e glabrescente na porção distal, tricomas aciculares, pluricelulares, articulados, alaranjados, $1-2 \mathrm{~mm}$ compr. Lâmina 2-3 pinado-pinatífida, crescimento indeterminado; pinas alternas, ca. $14 \mathrm{~cm}$ compr., pecioluladas; pínulas 3-7,5 $\times$ 1-3 cm, palmado-lobadas a pinadas, articuladas, cobertas por tricomas pluricelulares, base do pediólulo não dilatada, 1-3 mm compr., segmentos proximais palmatilobados, base hastada, margens dentadas, ápice obtuso; nervuras livres.

Material examinado:III.1987, M. A. Ranal 412 (HUFU, SP); IV.1992, M. A. Ranal 553 (HUFU); XI.1998, M. A. Ranal 632 (HUFU); XI.1999, M. A. Ranal 914 (HUFU), 962 (HUFU); I.2000, M. A. Ranal 1015 (HUFU, SP); IX.2004, A. A. Arantes \& M. A. Ranal 1242 (HUFU, SP); XI.2004, A. A. Arantes \& M. A. Ranal 1366 (HUFU, SP).

Lygodium venustum apresenta distribuição ampla no neotrópico. Destaca-se entre as demais espécies que ocorrem no Panga, pelo hábito lianescente, segmentos proximais das pínulas palmatilobados, pínulas férteis com esporângios solitários no ápice dos segmentos (lobos) e esporângios cobertos por um falso indúsio.

$\mathrm{Na}$ EEP, Lygodium venustum ocorre no interior de formações florestais, como cerradão, matas seca e de galeria, bem como nas bordas destes ambientes.

\section{Agradecimentos}

Ao CNPq, pelo apoio financeiro na forma de bolsa de Pós-doutorado Júnior concedida à primeira autora.

\section{REFERÊNCIAS BIBLIOGRÁFICAS}

Arantes, A. A.; Prado, J \&. Ranal, M. A. 2007a. Macrothelypteris e Thelypteris subg. Cyclosorus (Thelypteridaceae) da Estação Ecológica do Panga, Uberlândia, Minas Gerais, Brasil. Revista Brasileira de Botânica 30(3): 411-420.

2007b. Thelypteris subg. Goniopteris e Meniscium (Thelypteridaceae) da Estação Ecológica do Panga, Uberlândia, Minas Gerais, Brasil. Hoehnea 34(1): 121-129. 
2008. Thelypteris subg. Amauropelta (Thelypteridaceae) da Estação Ecológica do Panga, Uberlândia, Minas Gerais, Brasil. Rodriguésia 59(1): 201-208.

Araújo, G. M., Barbosa, A. A. A., Arantes, A. A. \& Amaral, A. F. 2002. Composição florística de veredas no Município de Uberlândia, MG. Revista Brasileira de Botânica 25(4): 475-493.

Bridgewater, S.; Ratter, J. A. \& Ribeiro, J. F. 2004. Biogeografic patterns, $\beta$-diversity and dominance in the cerrado biome of Brazil. Biodiversity and Conservation 13(12): 2295-2318.

Castro, A. A. J. F.; Martins, F. R.; Tamashiro, J. Y. \& Shepherd, G. J. 1998. How rich is the flora of Brazilian cerrados? Annals of Missouri Botanical Garden 86: 192-224

Collinson, M. F. 1996. "What use are fossil ferns?" 20 years on: with a review of the fossil history of extant pteridophyte families and genera. In: Camus, J. M.; Gibby, M \& Johns, R. J. (eds.). Pteridology in perspective. Royal Botanic Gardens, Kew. Pp. 349-394.

Drummond, G. M.; Martins, C. S.; Machado, A. B. M.; Sebaio, F. A. \& Antonini, Y. (orgs.). 2005. Biodiversidade em Minas Gerais: um atlas para sua conservação. 2 ed. Fundação Biodiversitas, Belo Horizonte, 222p.

Fernandes, I. 2005. Cyatheaceae. In: Cavalcanti, T. B. \& Ramos, A. E. (orgs). Flora do Distrito Federal, Brasil. Vol. 4. Embrapa Recursos Genéticos e Biotecnologia, Brasília. Pp. 123-134.

Figueiredo, J. B. \& Salino, A. 2005. Pteridófitas de quatro reservas particulares do patrimônio natural ao sul da região metropolitana de Belo Horizonte, Minas Gerais, Brasil. Lundiana 6(2): 83-94.

Korall, P.; Pryer, K. M.; Metzgar, J. S.; Schneider, H. \& Conant, D. S. 2006. Tree ferns: monophyletic groups and their relationships as revealed by four proteincoding plastid loci. Molecular Phylogenetics and Evolution 39(3): 830-845.
Lellinger, D. B. 1989. The ferns and fern-allies of Costa Rica, Panama, and the Chocó. Part 1: Psilotaceae through Dicksoniaceae. Pteridologia 2A: 1-364.

2002. A modern multilingual glossary for taxonomic pteridology 3A. American Fern Society, Washington, 264p.

Mendonça, R. C.; Felfili, J. M.; Walter, B. M. T.; Silva Júnior, M. C.; Rezende, A. V.; Filgueiras, T. S. \& Nogueira, P. E. 1998. Flora vascular do cerrado. In: Sano, S. M. \& Almeida, S. P. (eds). Cerrado: ambiente e flora. Planaltina: Embrapa-CPAC. Pp. 289-556.

Mickel, J. T. 1962. A monographic study of the genus Anemia, subgenus Coptophyllum. Iowa State College Journal of Science 36(4): 349-482.

1981. Revision of Anemia subgenus Anemiorrhiza (Schizaeaceae). Brittonia 33(3): 413-429.

Mickel, J. T. \& Beitel, J. M. 1988. Pteridophyte Flora of Oaxaca, Mexico. Memoirs of The New York Botanical Garden 46: 1-568.

Mickel, J. \& Smith, A. R. 2004. Pteridophytes of Mexico. Memoirs of the New York Botanical Garden 88: 1-1070.

Mittermeier, R. A.; Fonseca, G. A. B.; Rylands, A. B. \& Brandon, K. 2005. A brief history of biodiversity conservation in Brazil. Conservation Biology 19(3): 601-611.

Moran, R. C. 1995a. Schizaeaceae. In: Davidse, G.; Souza, M. \& Knapp, S. (eds.). Flora mesoamericana. Vol. 1. Universidad Nacional Autónoma de México, Ciudad de México. Pp. 52-57. 1995b. Asplenium. In Davidse, G., Souza, M. \& Knapp, S. (eds.). Flora mesoamericana. Vol. 1. Universidad Nacional Autónoma de México, Ciudad de México. Pp. 93-103.

1995c. Cyathea. In: Davidse, G.; Souza, M. \& Knapp, S. (eds.). Flora mesoamericana. Vol. 1. Universidad Nacional Autónoma de México, Ciudad de México, 325p.

Myers, N.; Mittermeier, R. A.; Mittermeier, 
C. G.; Fonseca, G. A. B. \& Kent, J. 2000.

Biodiversity hotspots for conservation priorities. Nature 403: 853-858.

Øllgaard, B. 2001. Schizaeaceae. In: Harling, G. \& Andersson, L. (eds.). Flora of Ecuador. Göteborg, University of Göteborg, 66: 81-104.

Pichi-Sermolli, R. E. G. 1996. Authors of scientific names in Pteridophyta. Kew, Royal Botanic Gardens, 78p.

Prado, J. \& Labiak, P. H. 2003. Pteridófitas. In: Pirani, J. R.; Mello-Silva, R. \& Giulietti, A. M. (orgs.). Flora de Grão Mogol, Minas Gerais. Boletim de Botânica da Universidade de São Paulo 21(1): 25-47.

Ratter, J., Bridgewater, S. \& Ribeiro, J. F. 2003. Analysis of the floristic composition of the brazilian cerrado vegetation III: Comparison of the woody vegetation of 376 areas. Edinburgh Journal of Botany 60(1): 57-109.

Ribeiro, J. F. \& Walter, B. M. T. 1998. Fitofisionomias do bioma cerrado. In: Sano, S. M. \& Almeida, S. P. (eds.). Cerrado: ambiente e flora. EMBRAPA-CPAC, Planaltina. Pp. 89-168.

Schiavini, I. \& Araújo, G. M. 1989. Considerações sobre a vegetação da Reserva Ecológica do Panga (Uberlândia). Sociedade \& Natureza 1: 61-66.

Sehnem, A. 1974. Esquizeáceas. In: Reitz, R. (Ed.). Flora Ilustrada Catarinense. Parte I, fasc. Esqui. Herbário Barbosa Rodrigues. Itajaí, 78 p.

Silva, M. R. P. \& Barros, I. C. L. 2005. Schizaeaceae. In: Cavalcanti, T. B \& Ramos, E. E. (orgs). Flora do Distrito
Federal, Brasil, Vol. 4. Brasília: Embrapa Recursos Genéticos e Biotecnologia. Pp. 219-247.

Skog, J. E.; Zimmer, E. A. \& Mickel, J. T. 2002. Additional support for two subgenera of Anemia (Schizaeaceae) from data for the chloroplast intergenic spacer region trnL-F and morphology. American Fern Journal 92(2): 119-130.

Smith, A. R. 1995. Pteridophytes. In: Berry, P. E.; Holst, B. K. \& Yatskievych (eds). Flora of the Venezuelan Guayana. Vol. 2. Missouri Botanical Garden \& Timber Press. Pp: 30-46.

Smith, A. R., Pryer, K. M., Schuettpelz, E., Korall, P., Schneider, H. \& Wolf, P. G. 2006. A classification for extant ferns. Taxon 55(3): 705-731.

Sylvestre, L. S. \& Ramos, C. G. V. 2005. Aspleniaceae. In: Cavalcanti, T. B. \& Ramos, E. E. (orgs). Flora do Distrito Federal, Brasil. Vol. 4. Embrapa Recursos Genéticos e Biotecnologia, Brasília. Pp. 111-120.

Tryon, R. M. \& Stolze, R. G. 1989. Pteridophyta of Peru. Part I. 1. Ophioglossaceae-12. Cyatheaceae. Fieldiana Botany, New series, 27: 111-139.

Tryon, R. M. \& Tryon, A. F. 1982. Ferns and allied plants: with special reference to Tropical America. Springer-Verlag, New York, $857 \mathrm{p}$.

Wikström, N.; Kenrick. P. \& Vogel, J. C. 2002. Schizaeaceae: a phylogenetic approach. Review of Paleobotany and Palynology 119(1-2): 35-50. 